\title{
Safety Situation and Injury Status of Students in Schools, Ardabil-Iran
}

\author{
${ }^{1}$ Zahra Sepehri, ${ }^{2}$ Mahboub Sheikhalizadeh ${ }^{*}$ \\ ${ }^{1}$ Department of Physical Education and Sport Sciences, Tabriz Branch, Islamic Azad University, Tabriz, Iran. \\ ${ }^{2}$ Department of Physical Education and Sport Sciences, Ahar Branch, Islamic Azad University, Ahar, Iran.
}

\begin{abstract}
Background. Sports injuries emanating from low-standard sports facilities and equipment are concerning because they can result in time lost from sports participation and school, social costs, and the economic costs of medical care. Objectives. The aim of this study was to investigate the relationship between the safety situation and the injury status of students in Ardabil city schools, Iran. Methods. The study population consisted of all schools in Ardabil city. For data collection purposes, 153 checklists seeking to gauge the safety situation and the number of injuries among students were distributed among these schools. Results. The results from the Chi-square analysis indicated that, in general, there was a statistically significant relationship between the safety of the school sports areas and equipment on the one hand, and the frequency of injury incidence among the students on the other. With regard to the relationship between safety components and the factors involved in injury, Chi-square tests showed that among the five components of sport fields and equipment safety, only two components-namely sports ground and boundaries safety - had a significant relationship with the injury of students. Conclusion. Hence, the authorities need to pay more attention to school safety components in general and the safety of sports grounds and boundaries in particular.
\end{abstract}

KEY WORDS: Sports Ground, Boundaries Safety, Sport Fields, Injury, Student, School.

\section{INTRODUCTION}

The safety levels of sports fields and facilities are important issues for sports science specialists, sports medicine, and health authorities. Among the most important institutions in the context of the current and future career of students are the Ministry of Education and schools. The purpose of embedding physical education in school curriculums has been to ensure and maintain health and well-being among students through physical activity (1). Boonzajer Flaes et al.
(2016) listed some important negative consequences of physical inactivity, such as higher risks of being overweight or obese and the increased risk of suffering from the resulting short- and long-term negative health issues (2). She also listed the benefits of physical activity, top-most among which are increased cardiorespiratory fitness and muscular strength, reduced body fat, favourable cardio-metabolic disease risk profiles, and improved self-esteem. But in order to achieve the highest possible

*. Corresponding Author:

Mahboub Sheikhalizadeh

E-mail: m-sheykhalizadeh@iau-ahar.ac.ir 
benefit from these activities, the existence of a secure and safe environment with standard equipment is essential. The sports areas of schools are no exception in this regard and safety considerations are among the major issues taken into consideration in the discussion about school buildings and school fields. In fact, despite the health benefits, athletes are at risk of injuries during practice and competition, with a prior study reporting that high school athletes participating in nine popular sports sustained an estimated 1.4 million sports-related injuries annually (3-5). In a study examining the prevalence and causes of sports injuries in the high schools of Shahroud city, Rezvani et al. (2008) reported that $23 \%$ of student injuries are due to defects in vehicles and features, and 20\% is due to non-compliance with safety regulations (6). In another study it was found that collision with hard barriers such as boards, gates and tight surfaces led to severe injuries among hockey players (7). A recent research on amount and causes of sports injuries indicated that inexpensive sports equipment, such as shoe and non-standard sports halls flooring led to considerable number of injuries (8). Similar studies found the falling (9) and inappropriate sports environment, tools and non-standard equipment (10) as well as non-compliance with safety considerations in the construction of playgrounds and also the use of worn out and non-standard equipment (11) as the most important reasons for the occurrence of sports injuries. If the managers of the sports venues do not control the safety of the playing fields, they might be at risk of being accused about neglecting the health of athletes (12). More importantly, a lack of sufficient attention to the issue of injury prevention in schools could have some unpleasant consequences for students, including physical and psychological problems, reduced sportsmanship, increased drop-out rate and leaving the classroom, staying away from training programmes, and negative attitudes towards physical education $(6,13,14)$.

So, researchers take effective steps to understand the factors that cause injuries in an attempt to reduce the amount of athletic injury and its negative consequences (especially, impairing team performance, and wasting financial and human capital). In doing so, they highlight the role of managers as well as risk management in sports (15). The financial costs are more important in the case of professional athletes who participate in school sports competitions. The costs incurred on treating the injured athlete and ensuring his return to racing includes a wide range of direct and indirect costs. The direct costs include all hospital and non-hospital expenses that an athlete or a sports centre bears. Meanwhile, indirect costs include the number of days of absence from competition due to injury, adversely influencing team performance $(16,17)$, as well as the athlete's daily cost to reach peak fitness and get back their race status. Although the exact details of quantity, quality, and injury are not known, it seems that athletes faced certain injuries in sports training and participation in competitions, according to the nature of the sport (18). The lack of awareness of athletes and coaches, as well as the lack of careful planning for the prevention of sports injuries, has led to the early retirement of some elite athletes. The aim of this study was to investigate the relationship between the safety situation and the injury status of students in Ardabil city schools, Iran.

\section{MATERIALS AND METHODS}

Participants. The research method was descriptive and of the correlation type. The population of the study included all public and private schools in regions I and II of Ardabil city. Given that about 589 schools in the mentioned regions are working and using randomized cluster sampling, 265 schools were selected as the sample. In visiting these schools to collect data, it was found that some training centers served two educational levels (e.g. primary and secondary schools) at the same time. In order to avoid mixing statistics, these schools were excluded from the sample list. Only schools with one time shift and one gender were considered. This reduced the sample size to 182 cases. Finally, with regard to the non-delivery of the completed questionnaires $(\mathrm{n}=19)$ by some schools (despite conducted follow-up), and considering distorted and incomplete questionnaires (10 cases), the total number of questionnaires considered as the main data in this study was 153 . More specifically, the following instruments were used to measure the variables. 
Safety Checklist of Sports Fields. The checklist developed by Farsi et al. (2006) was used in this study (19). The checklist contains 93 questions that were designed in five parts, with 11 questions about the safety of sports grounds, 27 questions about the equipment and facilities, 17 questions related to the safety of installations and covers, 23 questions related to the design and dimensions, and 15 questions related to privacy and lines. It should be noted that the validity of this checklist has already been measured. The reliability of the checklist was obtained through Cronbach's alpha coefficient (0.76). Table 1 shows the distribution of questions in this questionnaire.

Table 1. Distribution of Questions in the School Safety Checklist

\begin{tabular}{lc}
\hline Safety components & $\begin{array}{c}\text { Number of } \\
\text { questions }\end{array}$ \\
\hline $\begin{array}{l}\text { Inside and surfaces } \\
\text { components }\end{array}$ & 11 \\
\hline Privacy and lines component & 15 \\
\hline $\begin{array}{l}\text { Covers and facilities } \\
\text { components }\end{array}$ & 17 \\
\hline $\begin{array}{l}\text { Design and dimensions } \\
\text { component }\end{array}$ & 23 \\
\hline Equipment component & 27 \\
\hline Total & 93 \\
\hline
\end{tabular}

Scoring the checklists was done through the following steps: Any Yes and No answers were awarded 2 points and 1 point, respectively. The resulting score was calculated to give a total score on safety for each education unit. Then, the score obtained by each of the elements of the checklist was calculated separately.
Sports Injury Checklist. This checklist was used to assess the incidence of student injuries in the sample schools. The validity of this questionnaire was approved by five professors in sports management. This questionnaire contains information about the number of injuries and factors involved in the damage that are directly associated with the safety components. The reliability of the questionnaire was 0.81 , as measured by Cronbach's alpha, thus reflecting a high degree of reliability; hence, the results can be trusted. A Chi-square test was used to analyse the data.

Data Collection. After obtaining the consent of the people, the study was performed. The participants were introduced to the purpose of the study and informed how to complete the checklists. Regarding the ethical considerations, they were assured that the information would be used only for the research purpose and would be kept confidential.

Statistical analysis. A Chi-square test was used to examine the relationship between the safety situation of schools and the injury status of the students. Data was analyzed using SPSS software at $\mathrm{p}<0.05$.

\section{RESULTS}

Based on data from Table 2, it can be seen that the Chi-square with $\mathrm{df}=9$ was 17.403 $(p=0.043)$. Since the significance level was less than 0.05 , we can conclude that there was a significant relationship between the schools' safety levels and the injuries among students in these schools.

Table 2. Chi-Square Test to Investigate the Relationship between Safety and Injury

\begin{tabular}{cccc}
\hline & Value & df & Sig. \\
\hline Chi-square statistic & 17.403 & 9 & $0.043^{*}$ \\
Likelihood ratio & 18.807 & 9 & $0.027^{*}$ \\
Linear with linear relationship & 0.338 & 1 & 0.561 \\
\hline
\end{tabular}

*. Significant at $\mathrm{p}<0.05$.

Table 3 below shows the relationship between the various safety components under consideration and the injury of the participants.
Based on the table, we can say that the Chisquare with $\mathrm{df}=9$ was $16.093(\mathrm{p}=0.020)$. The significance level was less than 0.05 . So, there 
was a significant relationship between schools' sports safety and the injury status of the pupils.

It can be observed that the Chi-square related to the relationship between equipment safety and injury with $\mathrm{df}=9$ was 9.635 $(\mathrm{p}=0.381)$. Since the significance level was above 0.05 , it can be concluded that there was no significant relationship between the variables equipment safety and injury amount. Table 3 also shows that the Chi-square related to the relationship between the safety of installations and injury with $\mathrm{df}=9$ was 10.493 $(\mathrm{p}=0.312)$. As the significance level was more than 0.05 , it can be concluded that there was no significant relationship between the variables of safety of installations and the number of injuries of these schools' students. The Chisquare related to the relationship between design safety and injury with $\mathrm{df}=9$ was 4.660 $(p=0.863)$. The significance level was more than 0.05 , which means that there was no significant relationship between the variables of design safety and the number of injuries of these schools' students. The related Chi-square with $\mathrm{df}=9$ was 19.198 ( $\mathrm{p}=0.024)$. Regarding the significance level, which was less than 0.05 , it can be concluded that there was a significant relationship between the safety of sport boundaries and the number of injuries of these schools' students.

Table 3. Chi-square Test to Investigate the Relationship between Safety components and Injury

\begin{tabular}{cccc}
\hline Safety components & Chi-square statistic & df & Sig. \\
\hline Ground Safety & 19.739 & 9 & $0.020^{*}$ \\
Equipment Safety & 9.635 & 9 & 0.381 \\
Facility Safety & 10.493 & 9 & 0.312 \\
Design safety & 4.660 & 9 & 0.863 \\
Boundaries Safety & 19.198 & 9 & $0.024^{*}$ \\
\hline
\end{tabular}

\section{DISCUSSION}

The aim of this study was to investigate the relationship between the safety situation and the injury status of students in Ardabil city schools, Iran. The results showed that the safety levels in the field of sports are very alarming. The factors considered included flat land, no cracks in the earth, lack of gravel on land, lack of inequality, installed rods inside land, etc. The findings revealed a significant relationship between these factors and the injury of students. The results of this study were consistent with the results of Ghafouri et al. (2001), Ghadimi Ilkhanlar, Baloochi, and Niknejad (2010), Roderick (2004), Boyce et al. (1984), and Arnason et al. (2004), who reported the mechanism of striking as the biggest cause of sports injuries in athletes on the fields (20-24). The results of Ghafouri et al. (2001) showed that a relatively significant percentage of injuries are due to athletes falling (23). Farsi et al. (2006), on the other hand, found the highest safety factor for sport fields and announced it as desirable (19). However, due to the low security inside the fields in this study and the significant relationship with the number of injured students and the previous results of researches, it seems that this low safety level can potentially cause harm to students and sportsmen. It is expected that by overcoming existing deficiencies in the field of sport, while enhancing the safety, we can prevent the problems that sometimes seem irreparable. The results showed no significant relationship between the accessories and sports equipment and the injury. Despite these findings, it should be noted that school safety has not been given priority in past years. Hence, this requires the serious attention of the authorities. Farsi et al. (2006) noted that the lack of safe equipment used in the games causes fatal injuries (19). Moreover, it has been mentioned that the collision of athletes with the crossbar and other equipment, in rare cases, leads to their death. The results of previous research shows that using unhealthy or even inadequate equipment and facilities gives rise to injuries in students and athletes, and to the loss of student efficiency in training sessions (16).

Meanwhile, the supplies and sports equipment in this study had a relatively high 
safety level; hence, a significant positive relationship was observed between equipment safety and students' injuries. Nevertheless, the authorities are expected to consider equipment safety in an attempt to decrease the number of sport accidents. The results of the data analysis showed no significant relationship between facilities and sports coverage and the number of injuries in students. Farsi et al. (2006) concluded that the low safety level in sport facilities cause damage and injury to athletes (19). According to the results of previous studies and the low standards of sports fields in this study, it is necessary that all the cases that can cause injury be identified and appropriate measures should be taken to improve them. This includes installing net around the playing fields, considering shields around the electricity grid, designing special covers for water and gas pipes for the prevention of collision with students as well as with sports vehicles, installing railings on stairs and balconies, etc.

The last reported case of emergency exits was at the Japan-Iran game at the Azadi Stadium, where the enormous influx of spectators resulted in the death of seven people and a great number of fans were injured. The results indicated a significant relationship between boundaries and lines and students' injuries. Farsi et al. (2006) showed that the design and dimensions factor has the lowest safety standard in sports spaces (19).

\section{CONCLUSION}

It seems that the reason for the poor safety status of sport fields in this research was the poor planning of the education sector in the field of sports, lack of necessary funds to enhance and improve the safety measures, lack of consideration in the occurrence of accidents, and lack of sufficient information regarding safety on the part of authorities as well as physical education teachers. It should be noted that in some schools under consideration good results have been achieved concerning the safety of sports fields and sports facilities. These schools, though very few in number, take special care in improving safety standards. They have also taken remarkable steps to improve knowledge of their physical education teachers about strategies of minimizing the incidence of student injuries in sports fields with respect to existing standards and criteria.

Nevertheless, a more concrete and palpable improvement in the current status can be witnessed provided that authorities in the Ministry of Sport and Youth monitor school sports fields, comparing the safety standards there against the latest safety measures. Strict observation, if coupled with subsequent followup modifications, could enhance the safety of the sports fields and equipment. This would lead to a remarkable decrease in the incidence of injury.

\section{APPLICABLE REMARKS}

- Regarding the low safety status of the sports fields it is necessary to take major steps to standardize these fields.

- It is also mandatory for the sports equipment to have high quality and meet the required standards to prevent and decrease injury incidence.

- Ministry of Sports authorities as well as the officials in Ministry of Education should cooperate in this regard and take into account the latest findings of the scholars for more concrete and palpable improvement to take place.

\section{REFERENCES}

1. Hoseinpour E, Vahdani M, Kashef MM, Hazrati M. Epidemiology of sports injuries of students in physical education classes for guidance school and high school boys in city of Urmia. Sport Sciences Quarterly. 2014;5(12):89-103 [Article in Farsi].

2. Boonzajer Flaes SAM, Chinapaw MJM, Koolhaas CM, van Mechelen W, Verhagen EALM. More children more active: Tailored playgrounds positively affect physical activity levels amongst youth. Journal of Science and Medicine in Sport. 2016;19(3):250-4.

3. Pieter W. Martial Arts Injuries. In: Caine DJ, Maffulli N, editors. Epidemiology of Pediatric Sports Injuries. 48. Basel: Karger; 2005. p. 59-73. 
4. Rechel JA, Yard EE, Comstock RD. An Epidemiologic Comparison of High School Sports Injuries Sustained in Practice and Competition. Journal of Athletic Training. 2008;43(2):197-204.

5. Tirabassi J, Brou L, Khodaee M, Lefort R, Fields SK, Comstock RD. Epidemiology of High School SportsRelated Injuries Resulting in Medical Disqualification: 2005-2006 Through 2013-2014 Academic Years. The American journal of sports medicine. 2016;44(11):2925-32.

6. Rezvani MH, Balouchi R, Bahr Aloloum H, Nik Nezhad MR. Prevalence And Causes Of Sport Injuries Among Physical Education Students In Shahroud University Of Technology. Research On Sport Science. 2008;6(18):115-24 [Article in Farsi].

7. Ornon G, Fritschy D, Ziltener J-L, Menetrey J. Professional ice hockey injuries: a 4 years prospective study. British Journal of Sports Medicine. 2011;45(4):366-.

8. Gholami S, Mehdipour A, Azmsha T. Assessment and identify the Amount and causes of sports injuries: a case study in Footsall players. International Research Journal of Applied and Basic Sciences. 2012;3(4):708-12.

9. Aleman KB, Meyers MC. Mountain biking injuries in children and adolescents. Sports medicine. 2010;40(1):7790.

10. Verhagen EA, van Stralen MM, van Mechelen W. Behaviour, the key factor for sports injury prevention. Sports medicine. 2010;40(11):899-906.

11. Petridou E, Sibert J, Dedoukou X, Skalkidis I, Trichopoulos D. Injuries in public and private playgrounds: the relative contribution of structural, equipment and human factors. Acta paediatrica (Oslo, Norway : 1992). 2002;91(6):691-7.

12. Swan P, Otago L, Finch CF, Payne WR. The policies and practices of sports governing bodies in relation to assessing the safety of sports grounds. Journal of science and medicine in sport. 2009;12(1):171-6.

13. Dishman RK, McIver KL, Dowda M, Saunders RP, Pate RR. Motivation and Behavioral Regulation of Physical Activity in Middle School Students. Med Sci Sports Exerc. 2015;47(9):1913-21.

14. McGinnis J. Mortality trends and signs of health progress in the united states: Improving understanding and action. Jama. 2015;314(16):1699-700.

15. Fuller C, Drawer S. The application of risk management in sport. Sports medicine. 2004;34(6):349-56.

16. Gabbett TJ. The training-injury prevention paradox: should athletes be training smarter $<\mathrm{em}>$ and $</ \mathrm{em}>$ harder? British Journal of Sports Medicine. 2016.

17. Giza E, Micheli LJ. Soccer injuries. Medicine and sport science. 2005;49:140-69.

18. Farsi A, Zamani Sani H, Fathi Rezaee Z. To Survey and Compare Safety Standards of Sport Spaces and Equipment of Tehran Schools of Different Grades and to Provide Strategies to Eliminate Probable Problems and to Use them Properly. Journal of Sport Management. 2012;4(14):65-89 [Article in Farsi].

19. Farsi A, Helalizadeh M, Sayyah M, Rasekh N, Darabi H. An investingation into safety conditions in Iranian schools and suggestions to improve those conditions. Research on Sport Sciences. 2006;16:40-54 [Article in Farsi].

20. Arnason A, Sigurdsson SB, Gudmundsson A, Holme I, Engebretsen L, Bahr R. Risk factors for injuries in football. The American journal of sports medicine. 2004;32(1 Suppl):5s-16s.

21. Boyce WT, Sprunger LW, Sobolewski S, Schaefer C. Epidemiology of injuries in a large, urban school district. Pediatrics. 1984;74(3):342-9.

22. Ghadimi Ilkhanlar H, Baloochi R, Niknejad M. The Survey of Physical Education Teachers' Viewpoints on Causes and Prevalence of Sport Injuries at Schools. Journal of Sport Medicine. 2010;2(1):91-101 [Article in Farsi].

23. Ghafouri A, Sayah M, Rahimi M, Dehkhoda M, Arab Ameri E. A Study Of Determining The Freqvency Rate Of Sport Injuries In Athlete Students Participating In Olympiads Of Iranian Gouernmentals State Universuties During Summer 2000. Teb Va Tazkieh. 2001(40):43-50 [Article in Farsi].

24. Roderick LM. The ergonomics of children in playground equipment safety. Journal of safety research. 2004;35(3):249-54. 